\title{
The possible effect of SCNIA and SCN2A genetic variants on carbamazepine response among Khyber Pakhtunkhwa epileptic patients, Pakistan
}

This article was published in the following Dove Press journal:

Therapeutics and Clinical Risk Management

\author{
Haleema Rehana Nazish' \\ Niaz Ali' \\ Shakir Ullah ${ }^{1,2}$ \\ 'Institute of Basic Medical Science, \\ Khyber Medical University, Peshawar, \\ Khyber Pakhtunkhwa, Pakistan; \\ ${ }^{2}$ Center for Neuroscience, Shantou \\ University Medical College, Shantou, \\ Guangdong 51504I, People's Republic \\ of China
}

Purpose: SCN1A (3184A>G) and $S C N 2 A(56 G>A)$ gene encodes $\alpha$ subunit of the neuronal voltage-gated sodium channel, which is a target for carbamazepine (CBZ). Recent studies have demonstrated that polymorphism of SCN1A (3184A>G) and SCN2A $(56 G>A)$ was associated with use of CBZ. However, it has not been determined whether the polymorphism affects CBZ or other antiepileptic drug responsiveness. The aim of the study was to establish whether the $S C N 1 A(3184 A>G)$ and $S C N 2 A(56 G>A)$ polymorphisms of the SCN1A and SCN2A genes affect responsiveness to $\mathrm{CBZ}$.

Methods: $S C N 1 A(3184 A>G)$ and $S C N 2 A(56 G>A)$ gene polymorphisms were genotyped in 93 Khyber Pakhtunkhwa epileptic patients treated with CBZ. The association between CBZ responsiveness and the polymorphism was estimated by adjusting for clinical factors affecting the outcome of therapy. The number of seizure episodes was documented at baseline, and the therapy of each of the 93 patients was followed up. The plasma level of CBZ was determined using reverse-phase high-performance liquid chromatography. SCN1A and SCN2A genes were genotyped using RFLP. Data were analyzed using Graph Pad Prism 6.

Results: Mean age of the patients was $18.6 \pm 9.3$ at the $3 \mathrm{rd}$ month and $18.7 \pm 9.5$ at the 6 th month. The baseline dose of CBZ was $468 \pm 19.8 \mathrm{mg} / \mathrm{d}$ and titrated at the rate of $48 \pm 1.4$ and $4.0 \pm 0.2 \mathrm{mg} / \mathrm{d}$. The difference in plasma level of CBZ was significant $(P=0.004)$ between 3rd and 6th month among different genotypes of SCN1A gene in nonresponder and responder patients. At the 3rd month of the therapy, the poor responders were more likely $(P=0.003$ and $P=0.01)$ to have variants $(3184 A G$ and $3184 G G$ ) of $S C N 1 A$ gene. Similarly, poor responsders were more likely $(P=0.0007$ and $P=0.001)$ to have variant genotypes ( $56 \mathrm{GA}, 56 \mathrm{AA})$ of $S C N 2 A$ gene at the $3 \mathrm{rd}$ month of the therapy.

Conclusion: This study demonstrated a significant association between the SCN1A (3184 AG and $G G$ ) and $S C N 2 A(56 G A$ and $A A$ ) genotype with CBZ-nonresponsive epilepsy.

Keywords: carbamazepine, epilepsy, resistance, $S C N 1 A$ gene and $S C N 2 A$ gene polymorphisms, clinical response

\section{Introduction}

Epilepsy is a neurological disorder which is characterized by periodic episodes of fits and seizures. Carbamazepine (CBZ) and valproate are considered first-line drugs in the treatment of epilepsy in most parts of the world. Valproate is the drug of choice for generalized tonic-clonic seizure, absence seizure, and myoclonic seizures, while the treatment of choice for simple partial, complex partial, and secondary generalized tonic-clonic seizures is CBZ. ${ }^{1,2}$ Unfortunately, 30\% of epileptic patients are resistant to antiepileptic drugs (AEDs), ${ }^{3}$ posing a huge financial burden to the patients. ${ }^{4}$ It has been reported that personal genetic variations affect the response of a drug and the
Correspondence: Shakir Ullah Institute of Basic Medical Science, Khyber Medical University, Phase V, Hayatabad, Peshawar, Khyber Pakhtunkhwa, Pakistan Tel +923469850144

Emailshakir.ibms@kmu.edu.pk 
ultimate pharmacoresistance, if any. ${ }^{5}$ There are polymorphic genes encoding drug targets and drug-metabolizing enzymes that can be used to predict the targeted outcomes of AEDs. ${ }^{6}$ $\mathrm{CBZ}$ is one of the most economical AEDs that is used for the treatment of partial and generalized tonic-clonic seizures. ${ }^{7}$ Studies have shown that substantial interindividual variations in response still exist to $\mathrm{CBZ}$ therapy. ${ }^{8}$ However, genetic variations are considered one of the main factors that might be responsible for variable response to the drug therapy in individualized patients. ${ }^{9} S C N 1 A$ gene expresses the $\alpha$ subunit of voltage-gated sodium channel type 1 that is responsible for firing of neurons in the brain. ${ }^{10,11}$ These ion channels are molecular targets for many AEDs, ${ }^{12}$ which block ionic exchange through the respective channels. ${ }^{6,13}$ Sodium channels have a large pore-forming $\alpha$ subunit associated with two smaller $\beta$ subunits. ${ }^{10,14}$ Evidence suggests that AEDs mainly act by blocking the $\alpha$ subunit. ${ }^{13}$ Previous studies have documented that most of mutations in the sodium channel gene, SCN1A, have been associated with myoclonic epilepsy in infancy, and with familial epilepsy, ${ }^{15-17}$ with ultimate effectiveness of drug. ${ }^{15,18,19}$ The polymorphisms in $S C N 1 A$ and $S C N 2 A$ alter the sodium channels structure and functions relationship with AEDs, thereby rendering them insensitive to the blocking effect of AEDs. That is why some patients respond well to AEDs while others do not respond. ${ }^{15}$ It has been found that SCN1A polymorphisms are associated with CBZ-resistant epilepsy. ${ }^{19}$ SCN2A gene, (c.56G $>$ A), is related to AED resistance in north Indian epileptic patients. ${ }^{16}$ $S C N 1 A$ and $S C N 2 A$ gene polymorphisms have no effect on the pharmacokinetic of $C B Z$ but have an association with the pharmacodynamics of CBZ. SCN1A $(3184 A>G)$ encodes the Thr 1067 Ala and $S C N 2 A(56 G>A)$ encode Arg19Lys. There are certain genes called candidate genes that have a strong association with interindividual drugs response, but some genes are called contributing genes as these may affect the interindividual drug response by interaction with other genes. It has been demonstrated that SCN1A gene polymorphisms are potential risk factors for drug resistance. ${ }^{20}$ Bao et $\mathrm{al}^{21}$ also suggested that SCN1A gene polymorphisms are significantly associated with drug resistance.

\section{Aims of the study}

The current study was focused on finding out the association of SCN1A and SCN2A genes polymorphisms with poor response to $\mathrm{CBZ}$ therapy in epileptic patients of Khyber Pakhtunkhwa, Peshawar, Pakistan. It is important to mention here that such types of studies are carried out in most populations of the world with variable conclusions. This study was carried out for the first time in the Khyber Pakhtunkhwa, Pakistan, population, and so this will add new knowledge to the existing literature.

\section{Ethics approval and consent to participate}

The study was approved by the Ethics Board of the Khyber Medical University, Peshawar via approval no DIR/KMU-EB/AC/000165 and the study complied with Helsinki's declaration.

\section{Methods}

\section{Selection of patients}

Ninety three patients suffering from different types of epilepsies, without any comorbidity, were purposively enrolled in the study at Outpatient Department of Neurology, Government Lady Reading Hospital, Peshawar, Pakistan, from August 2015 to June 2017. They were prescribed CBZ for the first time. Medical history, careful physical examinations, and complete investigations were recorded on a standardized proforma by respective ward physicians. All patients signed written consents form after explanation of the steps and the aims of the study were made in their local language(s).

\section{Sample size calculation, study design, and protocols}

Sample size $(\mathrm{n}=80)$ were calculated at $95 \%$ CI, SD 4, and margin of error 1 . The $\alpha$ score was 0.025 , and $Z$ score was 1.95. The value of $\beta$ in sample size calculation is 0.8 . Keeping in view $20 \%$ dropout rate, the total patients included in the study was 93. Also, it was a hospital based longitudinal study done with a 6-month follow-up period. Baseline interviews were carried out for determining types, evaluation of seizures, and subsequent initiation of the CBZ therapy. All the enrolled patients were treated with CBZ (Tegrol 200 and $400 \mathrm{mg}$ ) monotherapy on the basis of their seizure control keeping in view their types of epilepsies. Patients were asked to visit the Outpatient Department of Neurology Department of Lady Reading Hospital, on a monthly basis, for monitoring of their clinical prognosis and following for adherence to CBZ therapy. The enrolled patients were evaluated at the $3 \mathrm{rd}$ and 6th month of the CBZ therapy for clinical scoring to assess epilepsy management and determine their mean plasma levels for CBZ. The doses of CBZ in patients with poor seizure control were escalated, based on patients' prognosis, by their respective ward/neurophysicians. The protocol of study is 


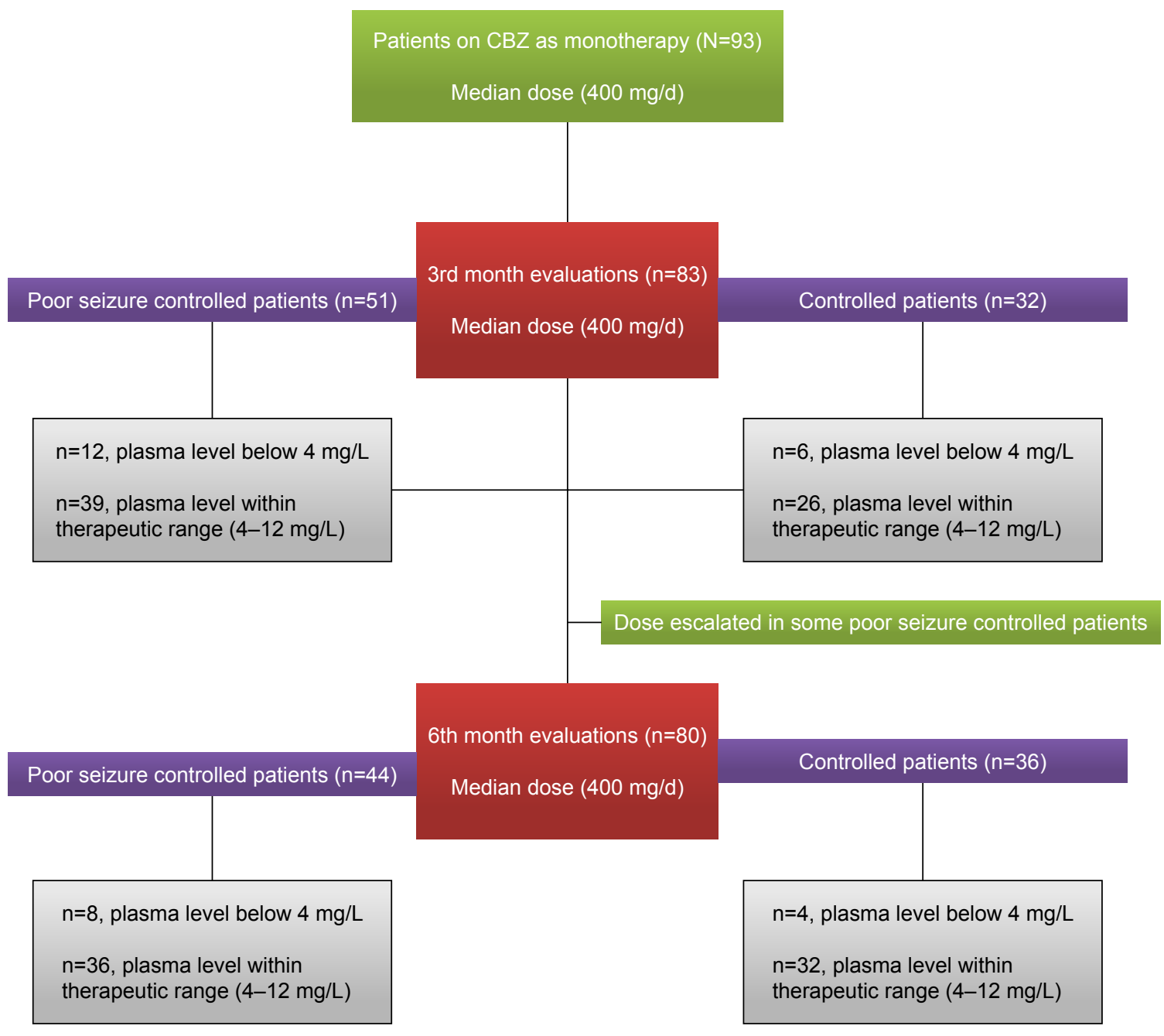

Figure I Schematic presentation of the study. Abbreviation: CBZ, carbamazepine.

comprehensively shown in Figures 1 and 2. According to guideline 6-month follow-up are short but most biochemical factors can be affected by CBZ within 6th month and more follow-up period affect the quality of life of patients. The patients whose seizure were not controlled were prescribed with other AEDs or switched to other AEDs without any further delay which affected the compliance and well-being of patients to seizure control. There were three patients that dropped out due to Steven-Johnson syndrome.

\section{Inclusion criteria}

Epileptic patients in whom CBZ as monotherapy was advised were enrolled in the study. Patients' willingness was checked before entering them into the study. The aim of the study in the context of local language was also explained to them. The seizure-provoking factors (sleep deprivations, drugs, etc) were controlled from date of enrollment to the end of the follow-up period. As epilepsy has multivariate etiology, we have tried to control the confounding factors that affect the clinical response.

\section{Exclusion criteria}

Patients who were not willing to participate in the study or were suffering from comorbidities were excluded from the study.

\section{Blood sampling}

Blood samples from each patient were taken for plasma therapeutic drug monitoring at end of 3rd and 6th month of the CBZ therapy. Timing of the blood sampling was 3 hours after administration of morning oral dose. We focused on $3 \mathrm{rd}$ and 6th month as we were also focusing on possible shift 


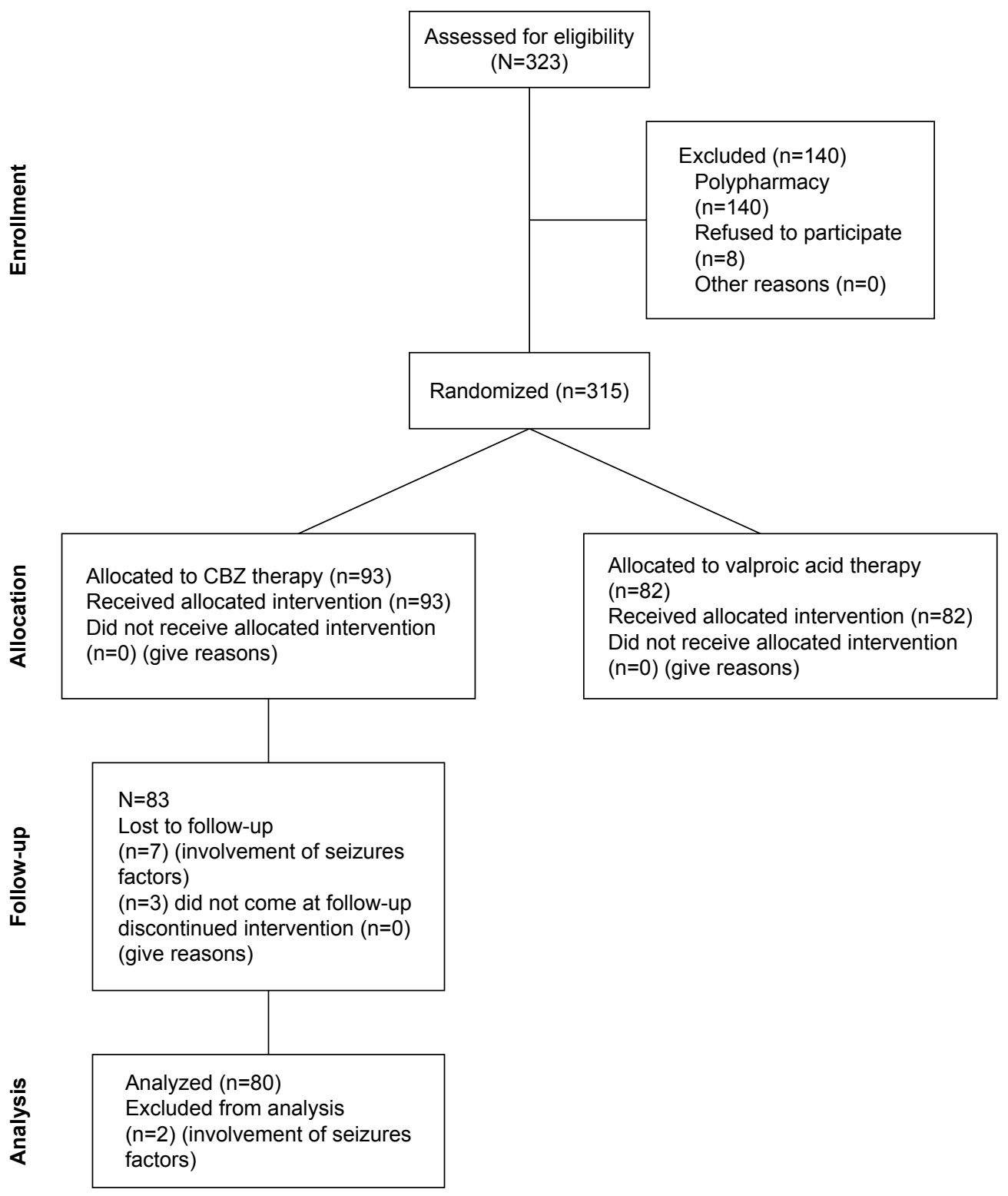

Figure 2 CONSORT diagram.

Abbreviation: CBZ, carbamazepine.

in other biochemical aspects, which may change during the course of therapy. Briefly, blood samples from the targeted patients were taken in gel tubes. The plasma was separated and stored for further analysis. For genotyping, blood samples were taken in EDTA tubes, stored at $8^{\circ} \mathrm{C}$ till used for DNA extraction and subsequent genotyping.

\section{Genotyping of SCNIA (rs229877I) and SC2A (rs I7I838I4) genes}

Genomic DNA was extracted using kit method (NucleoSpin ${ }^{\circledR}$ Blood, MACHEREY-NAGEL GmbH \& Co., Düren, Germany). Briefly, the extraction of DNA was carried out through a series of reactions which included deproteination of blood (proteinase K), lysis of blood cell (lysis buffer), purification of DNA (washing buffer), and finally elution of DNA (through elution buffer) according to standard protocols provided by the manufacturer. The extracted DNA was stored at $-20^{\circ} \mathrm{C}$ for further analysis. $\operatorname{SCN} 1 A($ c.3184 $A>G$ ) and $S C N 2 A$ (c. $56 G>A$ ) genes were amplified using gradient thermocycler. After amplification, the PCR products were run on $2 \%$ agarose gel and their sizes were assessed with a 50 bp ladder. $S C N 1 A$ (c.3184 A>G) gene was amplified by using primer 5-TGCACAAAGGAGTAGCTTATG-3 and primer 5-AGTCAAGATCTTTCCCAATTTCAG-3. The amplified product was digested using restriction enzyme PvuII. Similarly, SCN2A (c.56G>A) gene was amplified 
by using primer 5-AATCACCTTTTATTCTAATGGTC-3 and primer 5-CAGTGAAGGCAACTTGACTAAGA-3. The resulting product was digested using restriction enzyme ScrFI. The digested products of each amplified compound were run on $2 \%$ agarose gel, and respective fragments sizes were assessed with 50 bp ladder. ${ }^{22}$

\section{Analysis of plasma levels of CBZ}

Plasma level of CBZ was determined on adjusted dose in epileptic patients at the $3 \mathrm{rd}$ and 6 th month of therapy. Plasma from the centrifuged sample $(0.2 \mathrm{~mL})$ in gel tubes were added to $50 \mu \mathrm{L}$ of $25 \%$ ammonium hydroxide (BDH Laboratory Supplies, Poole, England) and $5 \mathrm{~mL}$ of chloroform (high-performance liquid chromatography grade) (Scharlab S.L., Barcelona, Spain). The samples were mixed in a mechanical shaker for 20 minutes and were centrifuged (PLC-05, Taiwan) at 3,000 rpm for 10 minutes. After centrifugation, the organic (chloroform) layer was transferred to another glass tube and evaporated by keeping the tube at $50^{\circ} \mathrm{C}$ in a water bath. The dry extract was reconstituted in $10 \mathrm{~mL}$ mobile phase. The extracted CBZ was analyzed using reverse-phase HPLC (RP-HPLC) (HPLC LC-20AT Shimadzu, Kyoto, Japan) coupled with UV detector SPD20A/20AV (Shimadzu) with a slight modifications in method of Dordević et al. ${ }^{23}$ In short, the mobile phase was a mixture of methanol (Chromasolv HPLC grade, Cerritos, CA, USA): demineralized water: glacial acetic acid 100\% (Merck KGaA, Darmstadt, Germany) at a ratio of 65:34:1 $(\mathrm{v} / \mathrm{v} / \mathrm{v})$ with a $\mathrm{pH} 5.6$. The flow rate was $0.8 \mathrm{~mL} / \mathrm{min}$ on a C18 column (SEA 18, $5 \mu \mathrm{m} 25 \times 0.46$ Mediterranean) with a load volume of $20 \mu \mathrm{L}$ of sample. Detection of CBZ was performed in the UV range at $\lambda_{\max } 220 \mathrm{~nm}^{23}$ The validation parameters such \% CV, precision, \% accuracy, and \% recovery were tested and validated on an intra- and interday basis (unpublished data).

\section{Measurement of patients' seizure control}

Seizure control was recorded in the form of reduction of frequencies of seizures using a standardized proforma. The numbers of seizures per week of the enrolled patients were recorded at baseline at the time of initiation of CBZ therapy (Tegral 200 and $400 \mathrm{mg}$ ), followed by evaluation of seizure control at the $3 \mathrm{rd}$ and 6 th month of the CBZ monotherapy. The patient compliance to the medication was checked by counting the pills remaining in the strip, and feedback from the patients was taken on a standardized patients' response sheet designed for this purpose in local language. Prognosis was determined as freedom from seizures after initiation of $\mathrm{CBZ}$ therapy and evaluated by time to time for clinical response. However, we present here prognosis at 3rd and 6th month of the therapy so as to correlate prognosis with plasma levels of CBZ therapy. Hence, the number of seizures was recorded in term of "number of seizures per week" on a prescribed proforma designed and standardized for the local context.

\section{Statistical analysis}

Possible changes in plasma levels of CBZ were compared after 3 and 6 months of the CBZ therapy among patients with different genotypes of SCN1A (c.3184 A $>$ G) and SCN2A (c.56G $>$ A) genes using one-way ANOVA followed by Tukey's test. Changes in plasma levels within different genotypes were also compared by using unpaired Student's $t$-test with Welchs' correction for high difference in SD. Differences in duration and frequencies of seizures in CBZ-resistant patients were determined using unpaired Student's $t$-test with Welchs' correction for high difference in SD. Association of variant genotypes of $S C N 1 A$ (c.3184 A>G) and $S C N 2 A$ (c. $56 G>A$ ) genes with patients with poor response to $\mathrm{CBZ}$ therapy and those with response to $\mathrm{CBZ}$ were determined using Chi-squared test with Yates' correction at 95\% CI, $P \leq 0.05$ for small sample size. All data were analyzed using Graph Pad Prism 6 (GraphPad Software, La Jolla, CA, USA) and G.Power 3.1 (Heinrich-Heine-Universität Düsseldorf, Düsseldorf, Germany).

\section{Results}

\section{Demographic data and treatment}

Patients' demographic data and types of epilepsies are shown in Table 1. Mean age of the patients was 18.6 \pm 9.3 at the 3rd month and $18.7 \pm 9.5$ at the 6th month. Generalized tonic-clonic seizures were the most frequently $(62 \%)$

Table I Demographic features of the enrolled patients

\begin{tabular}{|c|c|c|}
\hline Variables & $\begin{array}{l}\text { 3rd month of } \\
\text { CBZ therapy } \\
(n=83)\end{array}$ & $\begin{array}{l}\text { 6th month of } \\
\text { CBZ therapy } \\
(n=80)\end{array}$ \\
\hline Male, n (\%) & $4 \mathrm{I}(49.4)$ & $39(48.7)$ \\
\hline Female, n (\%) & $42(50.6)$ & $4 \mid(5 I .3)$ \\
\hline Age (years) $\pm S D$ & $18.6 \pm 9.3$ & $18.7 \pm 9.5$ \\
\hline $\begin{array}{l}\text { Generalized tonic-clonic } \\
\text { seizure, } n(\%)\end{array}$ & $63(76.0)$ & $62(77.5)$ \\
\hline Generalized tonic- seizure, n (\%) & $6(7.2)$ & $5(6.3)$ \\
\hline Atonic seizure, n (\%) & $4(4.8)$ & $4(5.0)$ \\
\hline Simple partial seizure, n (\%) & $6(7.2)$ & $5(6.3)$ \\
\hline Complex partial seizure, n (\%) & $2(2.4)$ & $2(2.5)$ \\
\hline $\begin{array}{l}\text { Secondary generalized complex } \\
\text { seizure, n (\%) }\end{array}$ & $2(2.4)$ & $2(2.5)$ \\
\hline
\end{tabular}

Abbreviation: CBZ, carbamazepine. 
Table 2 Dose and frequency of CBZ as monotherapy

\begin{tabular}{l|l|l|l|l|l}
\hline Variables & $\begin{array}{l}\text { Baseline } \\
(\mathbf{n = 9 3 )}\end{array}$ & $\begin{array}{l}\text { 3rd month } \\
(\mathbf{n = 8 3 )}\end{array}$ & $\begin{array}{l}\text { Dose titration } \\
\text { rate }\end{array}$ & $\begin{array}{l}\text { 6th month } \\
(\mathbf{n}=\mathbf{8 0})\end{array}$ & $\begin{array}{l}\text { Dose titration } \\
\text { rate }\end{array}$ \\
\hline $\begin{array}{l}\text { Dose }(\mathrm{mg} / \mathrm{d}) \\
\text { Frequency of dose }\end{array}$ & $468 \pm 19.8$ & $516 \pm 21.2$ & $48 \pm 1.4$ & $520 \pm 21.4$ & $4 \pm 0.2$ \\
OD, n (\%) & $38(40.9)$ & $20(24.1)$ & & $17(21.3)$ & \\
BID, n (\%) & $36(38.7)$ & $42(50.6)$ & & $38(47.5)$ & \\
TID, n (\%) & $19(20.4)$ & $21(25.3)$ & & $25(31.2)$ & \\
CBZ C/D ratio & - & $0.021 \pm 0.003$ & - & $0.024 \pm 0.04$ & - \\
\hline
\end{tabular}

Abbreviations: BID, twice a day; CBZ, carbamazepine; C/D, concentration dose ratio; OD, once a day; TID, three times a day.

reported type of epilepsy (Table 1). The initial baseline mean dose was $468 \pm 19.8 \mathrm{mg} / \mathrm{d}$, and the mean increased dose was $516 \pm 21.2 \mathrm{mg} / \mathrm{d}$ for better management of seizures at the $3 \mathrm{rd}$ month. Similarly, mean uptitrated dose was $520 \pm 21.4 \mathrm{mg} / \mathrm{d}$ at 6th month of the therapy (Table 2). CBZ concentrationto-dose ratio $(\mathrm{C} / \mathrm{D})$ was $0.021 \pm 0.003$ at $3 \mathrm{rd}$ month and $0.024 \pm 0.04$ at 6 th month of the therapy (Table 2).

\section{Plasma levels of $C B Z$ vs genotypes of SCNIA and SCN2A genes}

The plasma level of CBZ was compared among different genotypes of SCN1A c. $3184 A>G$ and $S C N 2 A$ c. $56 G>A$ genes in nonresponders and responders at $3 \mathrm{rd}$ and 6 th month of therapy (Figure 3A and B). The difference in plasma levels of $\mathrm{CBZ}$ was significant $(P=0.004)$ between $3 \mathrm{rd}$ and 6th month of the study among different genotypes of SCN1A c. $3184 \mathrm{~A}>\mathrm{G}$ genes in nonresponder and responder patients (Figure 3A). However, no significant $(P>0.05)$ changes were found in plasma levels of CBZ between 3rd and 6th month of the study among different genotypes of $S C N 2 A$ c. $56 G>A$ genes (Figure 3B). There were 18 patients whose plasma level was below the therapeutic range at the $3 \mathrm{rd}$ month of the therapy (Figure 1). However, the number of patients reduced to 12 whose plasma level was below the therapeutic range at 6th month of the therapy (Figure 1). The validation parameters of method development for the analysis of plasma level of CBZ were found within the recommended range on both interday and intraday basis (unpublished data).

\section{Control of seizures at 3rd month of the therapy}

After 3 months of CBZ therapy, 51 patients were found with poor response to CBZ. The epileptic patients' seizure control for 3 months is presented in Table 3. It has been observed that poor seizure-controlled patients were more likely to have variants ( $3184 A G$ and $3184 G G$ ) of SCN1A gene than patients in whom seizures were controlled $\left(\chi^{2}=6.9, P=0.003\right)$ (Table 3). Similarly, poor seizure-controlled patients were also more likely to have variants $(56 G A, 56 A A)$ of $S C N 2 A$ gene than patients in whom seizures were controlled $\left(\chi^{2}=14.4, P=0.0007\right)$ (Table 3).

\section{Control of seizures at 6th month of the therapy}

Following 6 months of CBZ therapy, it was evident that 34 patients were found with poor response to CBZ therapy

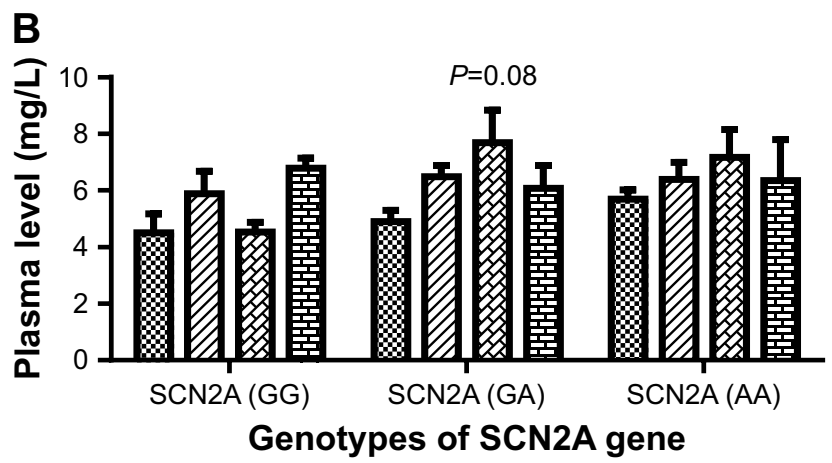

$\$ \infty \&$ 3rd month (non-responder)

Figure 3 Plasma level of CBZ vs different genotypes of SCNIA and SCN2A genes at the 3rd and 6th month of the therapy. Notes: (A) Plasma level of CBZ vs SCNIA genotypes. (B) Plasma level of CBZ vs SCN2A genotypes. *Significant changes. Abbreviation: $C B Z$, carbamazepine. 
Table 3 Mean plasma levels of CBZ in patients with SCN ( $\mathrm{I} A$ and $2 \mathrm{~A}$ ) gene polymorphisms with its relative frequencies in poor seizure-controlled and seizure-controlled patients at $3 \mathrm{rd}$ month of CBZ therapy

\begin{tabular}{l|l|l}
\hline $\mathbf{N}=\mathbf{8 3}$ & $\begin{array}{l}\text { CBZ-resistant } \\
\text { patients }(\mathbf{n}=\mathbf{5} \text { I) }\end{array}$ & $\begin{array}{l}\text { CBZ-responsive } \\
\text { patients }(\mathbf{n}=\mathbf{3 2})\end{array}$ \\
\hline Variables & Total & Total \\
\hline Number (\%) & $51(6 I .4)$ & $32(38.6)$ \\
Genotypes of SCNIA & & \\
(c.3I84 A > G) gene & 10 & 15 \\
3184AA & 23 & 10 \\
3184AG & 18 & 7 \\
3184GG & & \\
Genotypes of SCN2A & & \\
(c.56G>A) gene & 11 & 20 \\
56GG & 19 & 7 \\
56GA & 21 & 5 \\
56AA & & \\
\hline
\end{tabular}

Notes: SCNIA: AG and GG genotypes were more likely to be seen in CBZresistant patients compared to CBZ-responsive patients in Pakhtun population of Khyber Pakhtunkhwa $\left(\chi^{2}=6.9, P=0.03\right)$ when comparing total patients who are $C B Z$ resistant vs total patients who are CBZ responsive. SCN2A: GA and AA genotypes were more likely to be seen in CBZ-resistant patients compared to CBZ-responsive patients $\left(\chi^{2}=14.4, P=0.0007\right)$ when comparing total patients who are $C B Z$ resistant vs total patients who are $C B Z$ responsive.

Abbreviation: CBZ, carbamazepine.

(Table 4). Poor seizure-controlled patients were more likely to have variant (3184AG and $3184 \mathrm{GG}$ ) genotypes of $S C N 1 \mathrm{~A}$ gene than controlled patients $\left(\chi^{2}=9.1, P=0.01\right)$ (Table 4). Similarly, poor seizure-controlled patients were more likely to have variant genotypes (56GA, 56AA) than in controlled patients $\left(\chi^{2}=13.8, P=0.001\right)$ (Table 4$)$. It has been found

Table 4 Mean plasma level of CBZ in patients with SCN ( $\mathrm{A}$ and $2 \mathrm{~A}$ ) gene polymorphisms with its relative frequencies in poor seizure-controlled and seizure-controlled patients at 6th month of CBZ therapy

\begin{tabular}{l|l|l}
\hline $\mathbf{N}=\mathbf{8 0}$ & $\begin{array}{l}\text { CBZ-resistant } \\
\text { patients }(\mathbf{n}=\mathbf{4 4})\end{array}$ & $\begin{array}{l}\text { CBZ-responsive } \\
\text { patients }(\mathbf{n}=\mathbf{3 6})\end{array}$ \\
\hline Variables & Total & Total \\
\hline Number (\%) & $44(55)$ & $36(45)$ \\
Genotypes of SCNIA & & \\
(c.3I84 A $>$ G) gene & 10 & 19 \\
3184AA & 18 & 12 \\
3184AG & 16 & 5 \\
3184GG & & \\
Genotypes of SCN2A & \\
(c.56G $>$ A) gene & 10 & 18 \\
56GG & 18 & 11 \\
56GA & 16 & 7 \\
56AA & & \\
\hline
\end{tabular}

Notes: SCNIA: AG and GG genotypes were more likely frequent in CBZ-resistant patients compared to $C B Z$-responsive patients $\left(\chi^{2}=9.1, P=0.01\right)$ when comparing total patients who are CBZ resistant vs total patients who are $C B Z$ responsive. SCN2A: GA and AA genotypes were more likely frequent in CBZ-resistant patients compared to CBZ-responsive patients $\left(\chi^{2}=13.8, P=0.001\right)$ when comparing total patients who are $C B Z$ resistant vs total patients who are $C B Z$ responsive.

Abbreviation: $C B Z$, carbamazepine. that variant genotypes $(3184 A G, 3184 G G)$ of $S C N 1 A$ gene and $(56 G A$ and $56 A A)$ of $S C N 2 A$ gene in resistant patients at $3 \mathrm{rd}$ month of the therapy also remained resistant at the 6th month of CBZ therapy. Differences in frequency of seizures per week were not significant $(P>0.05)$ in $\mathrm{CBZ}$ nonresponsive patients in comparison of baseline with $3 \mathrm{rd}$ as well as baseline with 6th month of the therapy, especially in those with variant genotypes of $S C N 1 A$ and $S C N 2 A$ genes (Figure 4). This means that frequency of seizures per week was not affected in those patients with variant genotypes of $S C N 1 A$ and $S C N 2 A$ genes.

\section{Discussion}

It has been found that generalized tonic-clonic seizure was the most frequent type of seizure among the enrolled patients. It was obvious that $\mathrm{CBZ}$ is the drug of choice for simple partial, complex partial, and also generalized tonic-clonic seizures in most parts of the world. ${ }^{2}$ Epilepsy incidence was higher in male patients as compared with female patients. $S C N 1 A$ and $S C N 2 A$ genes polymorphisms have an association with pharmacodynamics but not with pharmacokinetics and plasma levels of CBZ. ${ }^{19}$ We found that the shift in the plasma levels of $\mathrm{CBZ}$ at 3rd month of the therapy was significant however, difference was not significant among the wild ( $3184 A A$ and $56 G G$ ) of SCN1A and SCN2A genes in responder and nonresponder patients. The changes in the plasma levels of $\mathrm{CBZ}$ in variant genotypes (3184AG, $3184 G G$ ) of $S C N 1 A$ gene were significant in responders and nonresponders. However, changes in the plasma levels of CBZ were not significant in responders and nonresponders in variant genotypes $(56 G A, 56 A A)$ of $S C N 2 A$ gene. So, it has been suggested that a shift in plasma level of CBZ is not consistent among different genotypes of SCN1A and SCN2A genes at 3rd and 6th month of the therapy. Ebid et $\mathrm{al}^{24}$ reported that therapeutic steady state did not guarantee clinical effectiveness of a drug. It has been found that variant genotypes (3184AG, 3184GG and 56GA, 56AA) of SCN1A and $S C N 2 A$ genes were associated with poor response to $\mathrm{CBZ}$ at 3rd as well as 6th month of the therapy. However, there are controversies with regard to clinical outcomes with respect to variant genotypes $(3184 A G, 3184 G G$ and $56 G A$, $56 A A)$ of $S C N 1 A$ and $S C N 2 A$ genes. ${ }^{25}$ However, Abe et al ${ }^{19}$ have shown that variant genotypes of $3184 A G, 3184 G G$ and $56 G A, 56 A A$ of $S C N 1 A$ and $S C N 2 A$ genes, respectively, are associated with poor response to CBZ. Recently, a common polymorphism in SCN1A was shown to be significantly associated with maximum doses of CBZ serum concentrations at maintenance dose in English and Chinese patient cohorts. ${ }^{18,26} S C N 1 A$ and $S C N 2 A$ gene polymorphisms have 


\section{Frequency of seizure in nonresponder patients}

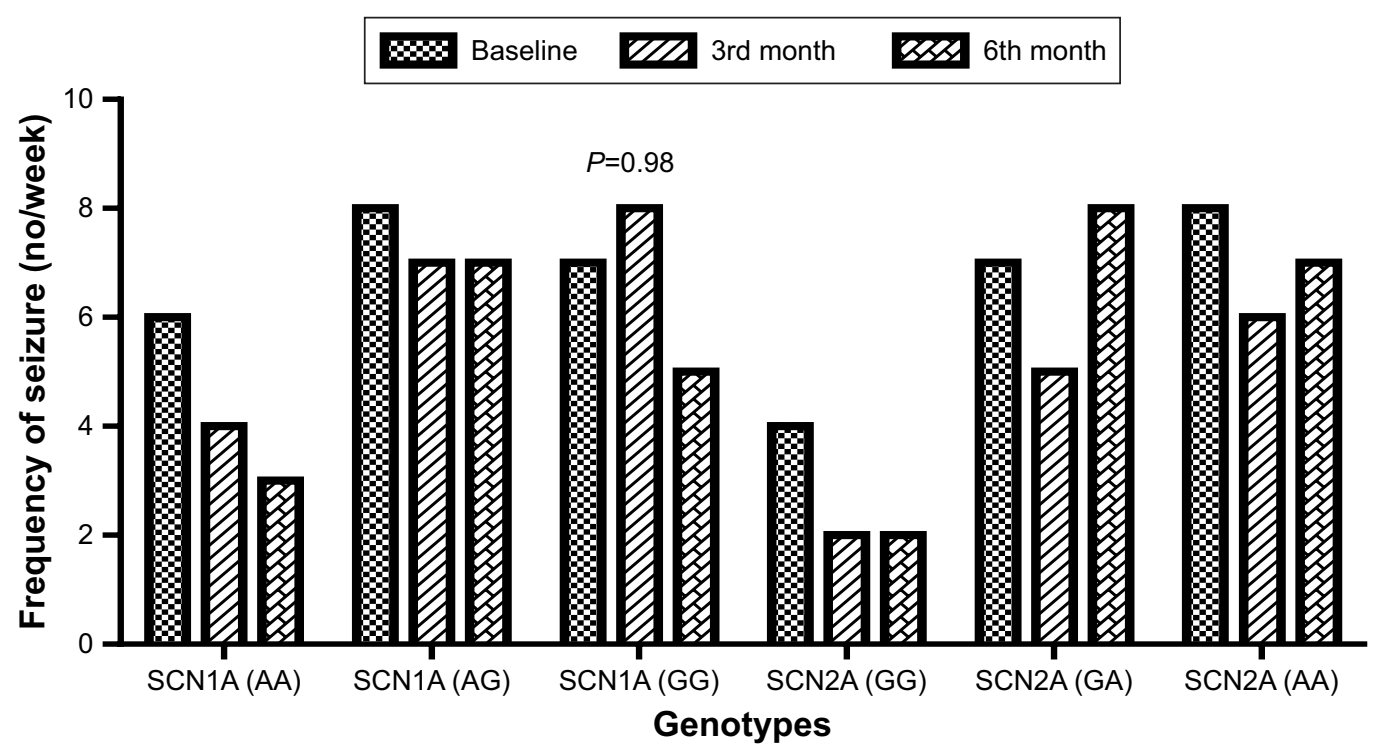

Figure 4 Duration of seizures per week in nonresponder patients to CBZ on 3rd and 6th month of the therapy. Abbreviation: CBZ, carbamazepine.

been associated with drug-resistant epilepsy, but these reports have not been consistent so far in many studies. Such discrepancies are also related to the other factors apart from genes polymorphisms. It has been found that there was no significant reduction in the number of seizures per week in poor seizure-control patients who have variant genotypes of SCN1A and SCN2A polymorphisms despite the fact that all seizure-provoking factors (deprivation of sleep, anxiety, seizure inducing drugs, etc) were strictly controlled for. This was done because these factors affect the clinical response of AEDs and lead to bias in the conclusion of the study. However, quite a high reduction in the number of seizures was found in those with wild genotypes of SCN1A and SCN2A.

\section{Conclusion}

Our study suggested that variant genotypes of $S N C 1 \mathrm{~A}$ (3184AG and $3184 G G$ ) and $S C N 2 A$ (56AG and $56 G G)$ genes are associated with poor response to CBZ monotherapy despite the fact that the patients' plasma levels were in the therapeutic range, which may point to possible pharmacodynamic interactions and are not related to a major shift in plasma levels of the drug in mean dose of $520 \pm 21.4 \mathrm{mg} / \mathrm{kg} / \mathrm{d}$.

\section{Consent for publication}

The patients gave consent to publish their data. Their confidentiality was maintained.

\section{Data sharing statement}

The datasets used during and/or analyzed during the current study are available from the corresponding author on reasonable request.

\section{Acknowledgments}

The authors also thank Professor Dr Adnan Khan and the Chief Executive of Govt. Lady Reading Hospital Peshawar for providing the opportunity to carry out this research work. The authors thank the Higher Education Commission of Pakistan (grant no 20-4092/NRPU/R\&D/HEC) for providing funds for the study.

\section{Author contributions}

HRN carried out experimental work as a PhD research scholar. SU and HRN prepared the first draft of manuscript. NA extensively revised the manuscript. He also designed the study and wrote the research project. All authors contributed equally during experiment, data analysis and writing the manuscript. All authors approved the final version of manuscript and agree to be accountable for all aspects of the work.

\section{Disclosure}

The authors report no conflicts of interest in this work.

\section{References}

1. Chadwick D. Valproate in the treatment of partial epilepsies. Epilepsia. 1994;35(Suppl 5):S96-S98. 
2. Kenyon K, Mintzer S, Nei M. Carbamazepine treatment of generalized tonic-clonic seizures in idiopathic generalized epilepsy. Seizure. 2014;23(3):234-236

3. Kwan P, Brodie MJ. Early identification of refractory epilepsy. NEngl J Med. 2000;342(5):314-319.

4. Cardarelli WJ, Smith BJ. The burden of epilepsy to patients and payers. Am J Manag Care. 2010;16(12 Suppl):S331-S336.

5. Emich-Widera E, Likus W, Kazek B, et al. CYP3A5*3 and C3435T MDR1 polymorphisms in prognostication of drug-resistant epilepsy in children and adolescents. Biomed Res Int. 2013;2013:1-7.

6. Kumari R, Lakhan R, Garg RK, Kalita J, Misra UK, Mittal B. Pharmacogenomic association study on the role of drug metabolizing, drug transporters and drug target gene polymorphisms in drug-resistant epilepsy in a north Indian population. Indian J Hum Genet. 2011 17(Suppl 1):S32.

7. Brodie M, Engel J, Lee P, de Boer H. European white paper on epilepsyCall to action. Epilepsia. 2003;44:4.

8. Kwan P, Brodie MJ. Effectiveness of first antiepileptic drug. Epilepsia. 2001;42(10):1255-1260.

9. Kasperaviciute D, Sisodiya SM. Epilepsy pharmacogenetics. Pharmacogenomics. 2009;10(5):817-836.

10. Catterall WA. Structure and function of voltage-gated sodium channels at atomic resolution. Exp Physiol. 2014;99(1):35-51.

11. Catterall WA, Channels S. Sodium channels, inherited epilepsy, and antiepileptic drugs. Annu Rev Pharmacol Toxicol. 2014;54:317-338.

12. Parker D, Sanders EJ, Burghardt KJ. Pharmacogenetics of antiepileptic drugs: A brief review. Ment Health Clin. 2016;6(1):28-34.

13. Kwan P, Poon WS, $\mathrm{Ng} \mathrm{HK}$, et al. Multidrug resistance in epilepsy and polymorphisms in the voltage-gated sodium channel genes SCN1A, SCN2A and SCN3A: correlation among phenotype, genotype, and mRNA expression. Pharmacogenet Genomics. 2008;18(11):989-998.

14. Baum L, Haerian BS, Ng HK, et al. Case-control association study of polymorphisms in the voltage-gated sodium channel genes SCN1A, SCN2A, SCN3A, SCN1B, and SCN2B and epilepsy. Hum Genet. 2014; 133(5):651-659.

15. Wang P, Zhou Q, Sheng Y, Tang B, Liu Z, Zhou B. Association between two functional SNPs of SCN1A gene and efficacy of carbamazepine monotherapy for focal seizures in Chinese Han epileptic patients. Zhong Nan Da Xue Xue Bao Yi Xue Ban. 2014;39(5):433-441.
16. Lakhan R, Kumari R, Misra UK, Kalita J, Pradhan S, Mittal B. Differential role of sodium channels SCN1A and SCN2A gene polymorphisms with epilepsy and multiple drug resistance in the north Indian population. Br J Clin Pharmacol. 2009;68(2):214-220.

17. Ebrahimi A, Houshmand M, Tonekaboni SH, Fallah Mahboob Passand MS, Zainali S, Moghadasi M. Two novel mutations in SCN1A gene in Iranian patients with epilepsy. Arch Med Res. 2010;41(3): 207-214.

18. Tate SK, Depondt C, Sisodiya SM, et al. Genetic predictors of the maximum doses patients receive during clinical use of the anti-epileptic drugs carbamazepine and phenytoin. Proc Natl Acad Sci U S A. 2005; 102(15):5507-5512.

19. Abe T, Seo T, Ishitsu T, Nakagawa T, Hori M, Nakagawa K. Association between SCN1A polymorphism and carbamazepine-resistant epilepsy. Br J Clin Pharmacol. 2008;66(2):304-307.

20. Margari L, Legrottaglie AR, Vincenti A, et al. Association between SCN1A gene polymorphisms and drug resistant epilepsy in pediatric patients. Seizure. 2018;55:30-35.

21. Bao Y, Liu X, Xiao Z. Association between two SCN1A polymorphisms and resistance to sodium channel blocking AEDs: a meta-analysis. Neurol Sci. 2018;39(6):1065-1072.

22. Deeparani T, Pillai MR, Elavazhagan T. Detection of MTHFR $\mathrm{C} 677 \mathrm{~T}$ and A1298C gene polymorphism in congenital heart disease. Middle-East J Scientific Res. 2009;4(2):127-132.

23. Dordević S, Kilibarda V, Stojanović T. Determination of carbamazepine in serum and saliva samples by high performance liquid chromatography with ultraviolet detection. Vojnosanit Pregl. 2009;66(5): 347-352.

24. Ebid AH, Ahmed MM, Mohammed SA. Therapeutic drug monitoring and clinical outcomes in epileptic Egyptian patients: a gene polymorphism perspective study. Ther Drug Monit. 2007;29(3): 305-312.

25. Haerian BS, Baum L, Kwan P, Tan HJ, Raymond AA, Mohamed Z SCN1A, SCN2A and SCN3A gene polymorphisms and responsiveness to antiepileptic drugs: a multicenter cohort study and meta-analysis. Pharmacogenomics. 2013;14(10):1153-1166.

26. Tate SK, Singh R, Hung CC, et al. A common polymorphism in the SCN1A gene associates with phenytoin serum levels at maintenance dose. Pharmacogenet Genomics. 2006;16(10):721-726.
Therapeutics and Clinical Risk Management

\section{Publish your work in this journal}

Therapeutics and Clinical Risk Management is an international, peerreviewed journal of clinical therapeutics and risk management, focusing on concise rapid reporting of clinical studies in all therapeutic areas outcomes, safety, and programs for the effective, safe, and sustained use of medicines. This journal is indexed on PubMed Central, CAS,

\section{Dovepress}

EMBase, Scopus and the Elsevier Bibliographic databases. The manuscript management system is completely online and includes a very quick and fair peer-review system, which is all easy to use. Visit http://www.dovepress.com/testimonials.php to read real quotes from published authors. 